\title{
Immobilization of Anammox biomass in sodium alginate
}

\author{
Anna Banach ${ }^{1, *}$, Aneta Pudlo ${ }^{1}$, and Aleksandra Ziembińska-Buczyńska ${ }^{1}$ \\ ${ }^{1}$ Environmental Biotechnology Department, Silesian University of Technology, Akademicka 2, \\ Gliwice, Poland
}

\begin{abstract}
Anaerobic ammonium oxidation (anammox) is a process of ammonium and nitrite conversion into nitrogen gas. Nowadays, anammox is applied into many wastewater treatment plants worldwide. However, anammox bacteria are characterized by a slow growth rate, which may cause problems in maintaining the biomass in the system. The promising technique which can help to maintain the biomass in the reactor and effectively prevent loss of anammox bacteria from a system is immobilization. Selection and optimization of the appropriate immobilization technique for investigated biomass is crucial for conducting an effective process. One of the ways for bacteria immobilization is gel entrapment. The main goal of the study was to test sodium alginate as an immobilization medium for anammox biomass. In the present study procedure of immobilization in sodium alginate was optimised, then the mechanical and chemical properties of the obtained pellets were investigated. Series of batch experiments revealed that immobilized anammox biomass was able to remove ammonia and nitrite nitrogen effectively. The calculated specific anammox activity (SAA) for immobilized anammox biomass was $0.18 \mathrm{~g} \mathrm{~N} \cdot \mathrm{gVSS}^{-1} \cdot \mathrm{d}^{-1}$, while for nonimmobilized biomass was $0.36 \mathrm{~g} \mathrm{~N} \cdot \mathrm{gVSS}^{-1} \cdot \mathrm{d}^{-1}$.
\end{abstract}

\section{Introduction}

Biological anaerobic ammonium oxidation (anammox) is a promising process for the treatment of ammonium - rich wastewater. The process is performed by anammox bacteria belonging to the phylum Planctomycetes [1]. Anammox process consumes less oxygen and involves no usage of external organic carbon in comparison to traditional nitrification denitrification process [2]. Nowadays, the most popular technology for anammox process application is DEMON $\AA$, which rely on partial nitrification and anammox processes. However, over the past decade many technologies have been developed and investigated for their applicability to the anammox process and several have made it into full-scale [3]. Despite obvious advantages, application of the anammox process is not difficulties free. Optimal temperature for anammox bacteria $\left(30-37^{\circ} \mathrm{C}\right)$ is higher than average temperature of wastewater $\left(10-15^{\circ} \mathrm{C}\right)$ [4]. Moreover, microorganisms conducted anammox process are characterized by low biomass yield. The doubling time of the anammox bacteria has been

\footnotetext{
${ }^{*}$ Corresponding author: anna.banach@polsl.pl
} 
reported to be 11-30 days [5-7]. One of the ways to cultivate slow-growing bacteria and develop a stable and high rate nitrogen removal anammox system is to immobilize biomass in a reactor. Under unfavorable conditions in operating system, anammox biomass growth is often inhibited, wherein fast growing heterotrophs start to dominate. Immobilization of anammox cells will lead to higher anammox biomass retention and will give possibility for anammox bacteria to growth inside the carrier. Higher concentration of anammox biomass will improve efficiency of wastewater deamonification. Nowadays, many modern wastewater treatment plants rely on immobilized microorganisms. Biological wastewater treatment is still the largest scale application of immobilized cell technology [8].

The selection of a carrier for immobilization is one of the key decisions to be made in the course of preparation of the immobilization process [9]. One of the ways of bacteria immobilization is gel entrapment. These immobilization techniques allows to manipulate the conditions of immobilization and let to obtain homogenous beads in volume and microorganisms location. Among water-soluble polymers, the matrixes most common for gel entrapment are alginates. Alginates are easy to handle, nontoxic to the environment and to the entrapped microorganisms. They are inexpensive and available at large quantities. Moreover, they are nontoxic for human [10, 11].

Many of authors have demonstrated that alginates may be used as a support media for effective cells immobilisation [12-13, 15-18]. Several authors focused on activated sludge immobilisation in sodium alginate $[12,13,19]$. Procedure of immobilization in sodium alginate is easy and do not cause significant changes in physicochemical conditions for immobilized microorganisms. Taking this factors into account, we chose sodium alginate as an immobilization medium for anammox biomass. An important aspect of the study was the selection of immobilization conditions, in the way to obtain as high concentration of microorganisms inside the beads as it is possible, due to a fact, that biomass concentration in the capsules probably will be connected with activity of microorganisms and efficiency of the process. In the present study we optimize immobilization method in sodium alginate for investigated biomass. Then, we tested mechanical and chemical properties of the pellets and checked the effect of immobilization on the short-term nitrogen removal.

\section{Materials and methods}

\subsection{Anammox biomass}

Anammox biomass for immobilization was taken from laboratory scale Sequencing Batch Reactor (volume of $5 \mathrm{~L}$ ) fed with simulate sewage medium with composition: $0.725 \mathrm{~g} \mathrm{NH}_{4} \mathrm{Cl} \mathrm{L}^{-1}, \quad 1.268 \mathrm{~g} \mathrm{NaNO}_{2} \mathrm{~L}^{-1}, \quad 0.048 \mathrm{~g} \mathrm{KHCO}_{3} \mathrm{~L}^{-1}, \quad 0.041 \mathrm{~g} \mathrm{KH}_{2} \mathrm{PO}_{4} \mathrm{~L}^{-1}$, $0.228 \mathrm{~g} \mathrm{MgSO}_{4} 7 \mathrm{H}_{2} \mathrm{O} \mathrm{L}^{-1}, 0.007 \mathrm{~g} \mathrm{FeSO}_{4} 7 \mathrm{H}_{2} \mathrm{O} \mathrm{L}^{-1}, 0.004 \mathrm{~g}^{2}$ EDA L ${ }^{-1}$. Synthetic medium was modeled on the nitrogen - rich wastewater composition and was modification of the simulate medium described by van de Graaf [14]. The reactor operated in stable conditions at a temperature of $30 \pm 1^{\circ} \mathrm{C}$ and $\mathrm{pH} 7.5 \pm 2$. Fluorescent is Situ Hybridization analysis revealed that Candidatus Brocadia and Candidatus Kuenenia were the most abundant anammox bacteria in the reactor (data not shown).

\subsection{Immobilisation in sodium alginate and properties of the pellets}

To anammox bacteria immobilization, sodium alginate was added to the concentrated anammox biomass in the ratio of $2: 1(\mathrm{v} / \mathrm{v})$. Then, the mixture was added by dropping through peristaltic pump to the calcium chloride solution. Bacteria were immobilized for $1 \mathrm{~h}$. Subsequently, obtained pellets were washed in deionized water. To optimise the 
immobilization conditions different concentration of sodium alginate: $1 \%, 1.5 \%, 2 \%, 2.5 \%$, $3 \%$ and calcium chloride: $2 \%, 3 \%, 4 \%, 5 \%$ were tested.

Alginate pellets were also tested in terms of chemical stability and mechanical strength. In the case of resistance to mechanical perturbation, the shape and size of the pellets as well as the biomass content inside the carrier were assumed as evaluation criteria. Mechanical strength was scrutinised by shaking out and spinning immobilized biomass gradually increasing speed at regular intervals with the 130-400 rpm and 1000-4400 rpm, respectively. To test chemical stability of obtained alginate pellets, immobilized biomass was stored in the simulate sewage medium and distilled water with differ $\mathrm{pH}$. The $\mathrm{pH}$ has been changed in the range $1-10$ by adding $\mathrm{NaOH}$ and $\mathrm{HCl}$ solutions.

\subsection{Batch test}

To evaluate SAA and reveal short-term nitrogen removal, immobilized and nonimmobilized biomass were investigated in series of batch tests. Batch experiment was performed in triplicate according to the method described by Tomaszewski et. al [20]. Tests were conducted for $3.5 \mathrm{~h}$ in $30^{\circ} \mathrm{C}$ with a $\mathrm{pH}$ value of 7.5 . During the tests, samples were taken every $0.5 \mathrm{~h}$ and were prepared for nitrogen concentration measurements by filtering through a $0.45 \mu \mathrm{m}$ syringe filter. The concentration of $\mathrm{N}-\mathrm{NH}_{4}$ and $\mathrm{N}-\mathrm{NO}_{2}$ was measured by photometric tests (MERCK Milipore) with a photometer (MERK Spectroquant ${ }^{\circledR}$ NOVA 60 ). The anammox activity was measured by calculating the linear descending slopes of $\mathrm{N}-\mathrm{NH}_{4}$ and $\mathrm{N}-\mathrm{NO}_{2}$ concentration. To calculate the SAA the removal rates for $\mathrm{N}-\mathrm{NH}_{4}$ and $\mathrm{N}-\mathrm{NO}_{2}$ were normalized by VSS (volatile suspended solids).

\section{Results}

\subsection{Immobilisation in sodium alginate and properties of the pellets}

The optimal immobilization conditions, at which the immobilized pellets showed adequate transparency and hardness, were found to be: concentrated biomass suspended in 4\% SA $(2: 1), 2 \%$ calcium chloride, $\mathrm{pH}=10.5$. Sodium alginate pellets are shown in Fig. 1.

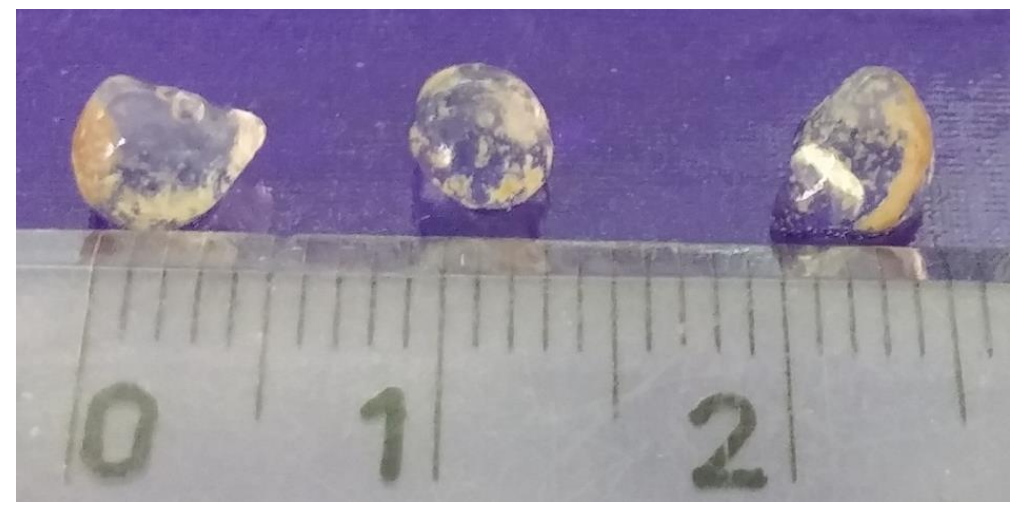

Fig. 1. Anammox biomass immobilized in sodium alginate.

Biomass has not been wash out from the carrier during the resistance to shaking and centrifugation tests. The immobilized biomass during shaking (up to $400 \mathrm{rpm}$ for $72 \mathrm{~h}$ ) did not show any structural changes. The first small shape changes took place during 
centrifugation of the pellets at $3000 \mathrm{rpm}$, whereas after centrifugation at $4400 \mathrm{rpm}$, there was a slight flattening of the pellets.

Sodium alginate was also resistance to changes in $\mathrm{pH}$. The pellets had a higher duration on acidic conditions, because at $\mathrm{pH}=1$ there was only a reduction in the size of the carrier in case of storage both in simulate sewage medium and distilled water. However, in $\mathrm{pH}$ above 8.5 the structure of the carrier storage in simulate sewage medium started to degrade. No degradation of immobilizates was observed in the distilled water adjusted up to $\mathrm{pH}=10$ by adding $\mathrm{NaOH}$.

\subsection{Nitrogen removal and SAA}

The Specific Anammox Activity was calculated based on the performed batch tests. The SAA for immobilized anammox biomass was $0.18 \mathrm{gN} \cdot \mathrm{gVSS}^{-1} \cdot \mathrm{d}^{-1}$, while SAA for nonimmobilized biomass was $0.36 \mathrm{gN} \cdot \mathrm{gVSS}^{-1} \cdot \mathrm{d}^{-1}$. Removal of nitrate nitrogen (III) and ammonia nitrogen by anammox biomass during batch tests is shown on Fig. 2 and 3.

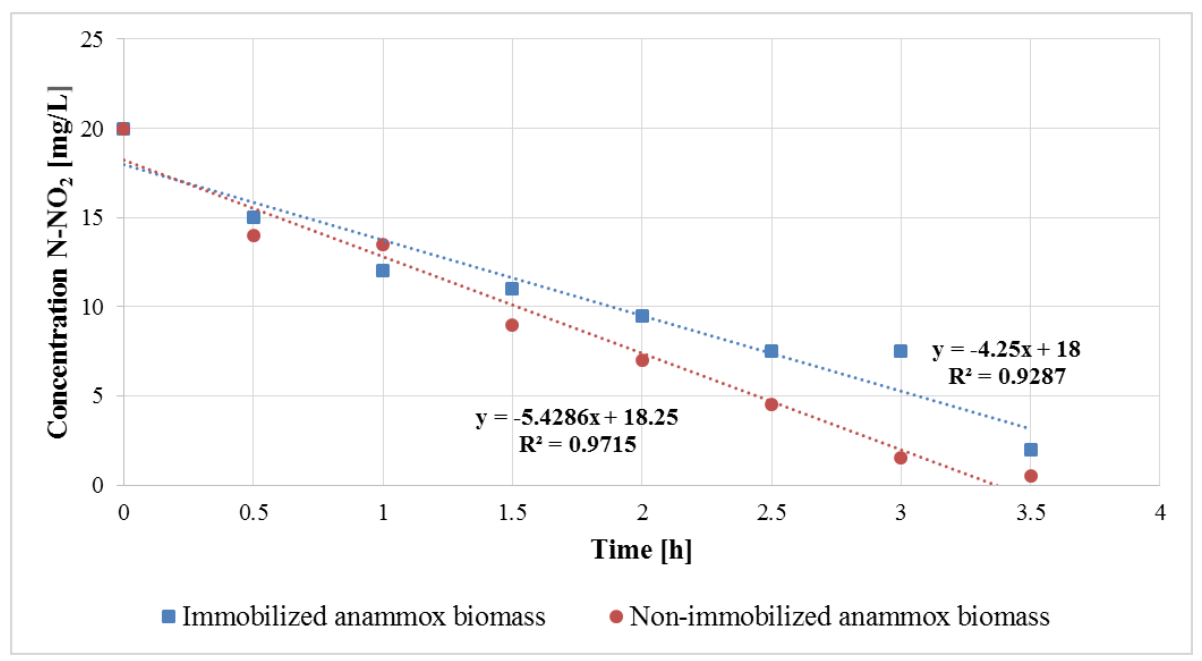

Fig. 2. $\mathrm{N}-\mathrm{NO}_{2}$ removal during batch test for the non-immobilized anammox biomass and anammox biomass immobilized in sodium alginate. 


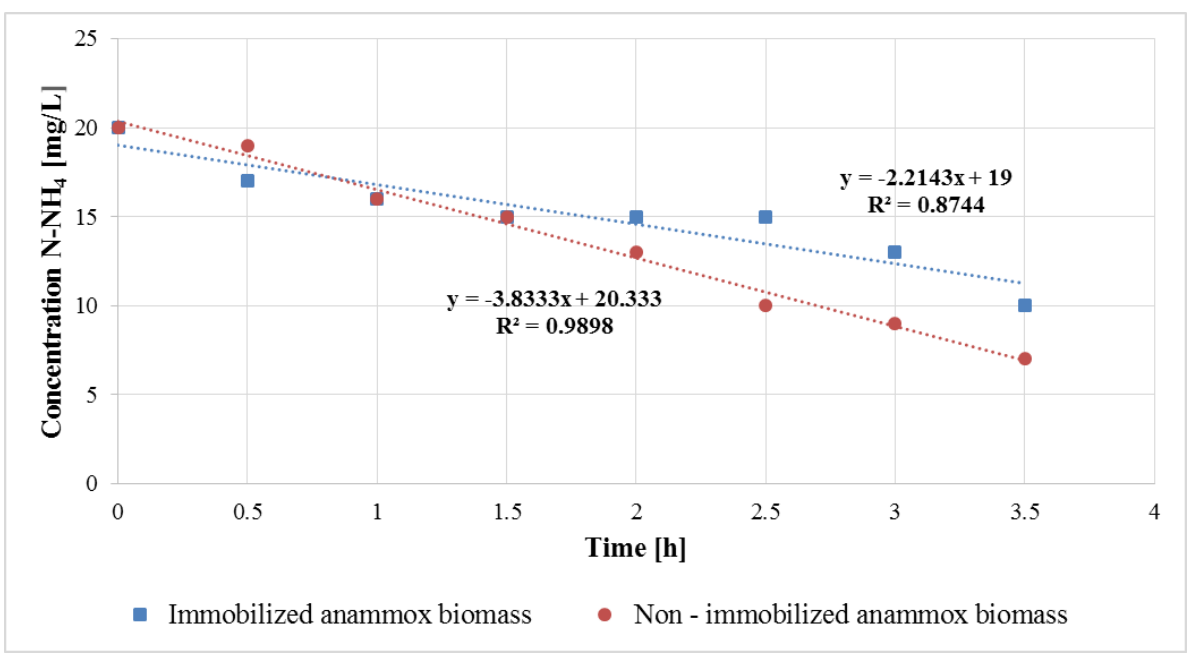

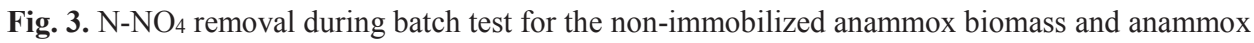
biomass immobilized in sodium alginate.

\section{Discussion}

The selection of the adequate carrier and immobilization method is crucial in terms of conducting a stable and efficient process. Different biomass immobilization techniques are examined for the effectiveness of wastewater treatment and the properties of immobilized material $[10,12,13,18,19]$. In the present study anammox biomass was immobilized in sodium alginate, which turned out to be a non-expensive and simple method. Mechanical and chemical stability are the most important factors in the selection of the carrier for immobilization. Immobilized alginate pellets were resistant for mechanical perturbation and for changes in $\mathrm{pH}$. In case of resistance to mechanical perturbation, shape and size of the pellets as well as the biomass content inside the carrier were assumed as evaluation criteria. Mechanical strength was tested by shaking out and spinning immobilized biomass, gradually increasing speed at regular intervals. Shape changes of the pellets took place during centrifugation the pellets above $3000 \mathrm{rpm}$. There was no biomass release from the alginate pellets both in the tested centrifugation range (1000-4400 rpm) and during the biomass shaking. Immobilization is the promising technique which can help to maintain the biomass in the reactor and effectively prevent loss of anammox bacteria in a system, therefore, it is important that the immobilized biomass is not washed out from the support during the process and the support is resistant for mechanical perturbations. The size and decomposition capacity of the pellets were tested in a different range of $\mathrm{pH}$. Sodium alginate pellets were resistant to $\mathrm{pH}$ changes and no decomposition were observed in acidic conditions in the case of simulate medium and both acidic and alkaline condition during storage the pellets in distilled water. However, in $\mathrm{pH}$ above 8.5 the structure of the pellets storage in simulate sewage medium started to degrade. This was probably due to the fact, that the simulated medium contained EDTA, which is easier soluble in the alkaline conditions and possess the chelating properties. The alginate gel can be easily converted into a solution by adding EDTA [21]. It is worth considering, if presence of the chelating agents in the wastewater could affect the stability of the alginate pellets in the context of a wider use of this method of immobilisation for wastewater treatment. Chelating agents such as EDTA can be classified as environmentally relevant and are present both in wastewater and almost all anthropogenically influenced streams and rivers in industrialized 
countries [22]. Dong's et al. [18] investigated the effect of $\mathrm{pH}$ of the ammonia nitrogen removal ability of the immobilised ammonia-oxidizing bacteria in sodium alginate. As in the case of the present study optimal sodium alginate concentration was found to be $4 \%$. The results obtained by Dong reveals that alkaline condition had greater influence on immobilized cells. Strong acid and strong alkali destroy the immobilized cells. In strong acid culture medium nutrients are unavailable for immobilized cells. In the present study we observed shrinking of the sodium alginate pellets in acidic conditions.

Immobilized anammox biomass was able to effectively remove ammonia and nitrite nitrogen. However, the SAA calculated based on the performed batch tests was significantly higher for non-immobilized biomass $\left(0.36 \mathrm{~g} \mathrm{~N} \cdot \mathrm{gVSS}^{-1} \cdot \mathrm{d}^{-1}\right)$, than for biomass immobilized in sodium alginate $\left(0.18 \mathrm{~g} \mathrm{~N} \cdot \mathrm{gVSS}^{-1} \cdot \mathrm{d}^{-1}\right)$. It was probably affected by limited access to the process substrates in the case of immobilized biomass. However, it is worth to notice that during continuous experiment immobilization would positively affect the stability of the process and will provide some protection from adverse $\mathrm{pH}$, temperatures and toxic shocks [23]. Yan and $\mathrm{Hu}$ [24] studied partial nitrification to nitrite for treating ammonium-rich organic wastewater by immobilized biomass system. The effect of $\mathrm{pH}$ and temperature on partial nitrification was evidently weakened in sodium alginate immobilized biomass beads.

Immobilization in sodium alginate may also help with rapid start-up of the anammox process. Start-up of anammox process requires strict control and often takes a long time due to slow growth rate of anammox bacteria. Immobilization seems to be the method with can help to overcome this problem. Ali et al. research [19] revealed that immobilization in polyvinyl alcohol-sodium alginate gel was found to be effective strategy for start-up of anammox reactor with minimal quantity of biomass. The column reactor, containing immobilized biomass $(0.33 \mathrm{~g} / \mathrm{VSS})$, started significantly faster than the reactor containing granulated biomass $(2.5 \mathrm{~g} / \mathrm{VSS})$.

This Study was supported by Polish National Science Centre grants. Grants no: UMO-2013/09/D/NZ9/02438 and UMO-2016/23/N/NZ9/02147.

\section{References}

1. B. Kartal, L. van Niftrik, J.T. Keltjens, H.J.M. Op den Camp, M. Jetten, Adv. Microb. Physiol. 60, 212-251 (2012)

2. Y.H. Ahn, Process Biochem. 41, 8, 1709-1721 (2006)

3. S. Lackner, E. Gilbert, S.E. Vlaeminck, A. Joss, H. Horn, M.C. Loosdrecht, Water Res. 55, 292-303 (2014)

4. T. Osaka, Y. Kimura, Y. Otsubo, Y. Suwa, S. Tsuneda, K. Isaka, J. Biosci. Bioeng. 114, 4, 429-434 (2012)

5. M. Strous, J.G. Kuenen, M.S. Jetten, 65, 7, 3248-3250 (1999)

6. C. Fux, V. Marchesi, I. Brunner, H. Siegrist, Water Sci. Technol. 49, 77-82 (2004)

7. B. Hyonkwan, P. Tanusree, K. Daeik, J. Jin-Young, Environ. Earth Sci. 75, 1443-1452 (2016)

8. V. Nedovic, R. Willaert (eds.), Kluwer Academic Publishers 121-139 (2004)

9. O.M. Zacheus, E.K. Iivanainen, T.K. Nissinen, M.J. Lehtola, P.J. Martikainen, Water Res. 34, 63-70 (2000)

10. S.C.S. Martins, C.M. Martins, S.T. Santaella, Afr. J. Biotechnol. 12.28 (2013)

11. L.E de Bashan, Y. Bashan, Bioresour. Technol. 101, 6, 1611-1627 (2010)

12. Y. Dong, Y. Zhang, B. Tu, Braz. J. Microb. 48, 515-521 (2017) 
13. J. Yan, M.S. Jetten, J. Rang, Y. Hu, Chemosphere 81, 669-673 (2010)

14. A.A. Van de Graf, P. de Bruijn, L.A. Robertson, M. Jetten, J. Kuenen, Microbiol. 142, 2187-2196 (1996)

15. A. Idris, W. Suzana, Process Biochem. 41, 5, 1117-1123 (2006)

16. P. Xiangliang, W. Jianlong, Z. Daoyong, Process Biochem. 40, 8, 2799-2803 (2005)

17. G. Simo, J. Vila, E. Fernández, V. Ruipérez, J. M. Rodriguez-Nogales, J. Agric. Food Chem. (2017)

18. Y. Dong, Y. Zhang, B. Tu, J. Miao, Ecol. Eng. 73, 809-814 (2014)

19. M. Ali, M. Oshiki, L. Rathnayake, S. Ishii, H. Satoh, S. Okabe, Water Res. 79, 147-157 (2015)

20. M. Tomaszewski, G. Cema, A Ziembińska-Buczyńska, Chemosphere 185, 439-444 (2017)

21. A. Shilpa, S.S. Agrawal, A.R. Ray, 43, 2, 187-221 (2003)

22. T.P. Knepper, Trend. Anal. Chem. 22, 10, 708-724 (2003)

23. M. Morita, N. Kudo, H. Uemoto, A. Watanabe, H. Shinozaki, Eng. Life Sci. 7, 587-592 (2007)

24. J. Yan, Y.Y. Hu, Bioresource Technol. 100, 8, 2341-2347 (2009) 